\title{
SOFTWARE EDUCACIONAL PARA O ENSINO DE INVENTÁRIO FLORESTAL
}

\author{
Rafael Romualdo Wandresen ${ }^{1 *}$, Henrique Soares Koehler², Sylvio Péllico Netto ${ }^{3}$, Carlos Roberto \\ Sanquetta ${ }^{4}$ \\ ${ }^{1 *}$ Universidade Federal do Paraná, Setor de Educação Profissional e Tecnológica, Curitiba, Paraná, Brasil, \\ rafael.wandresen@ufpr.br \\ ${ }^{2}$ Universidade Federal do Paraná, Pós-graduação em Engenharia Florestal, Curitiba, Paraná, Brasil, koehler@ufpr.br \\ ${ }^{3}$ Universidade Federal do Paraná, Pós-graduação em Engenharia Florestal, Curitiba, Paraná, Brasil, \\ sylviopelliconetto@gmail.com \\ ${ }^{4}$ Universidade Federal do Paraná, Departamento de Ciências Florestais, Curitiba, Paraná, Brasil, \\ carlos sanquetta@hotmail.com
}

\begin{abstract}
Resumo
Os processos de amostragem correspondem a um importante conteúdo na disciplina de Inventário Florestal dos cursos de Engenharia Florestal. Este artigo demonstra o desenvolvimento e o uso de um software de aprendizado que propõe ao estudante o exercício de 16 processos de amostragem diferentes. A aplicação desenvolvida não precisa ser instalada e é acessada pela Internet. Os dados utilizados são gerados individualmente para cada aluno e a correção dos exercícios é realizada de forma automática. O modelo APDIA (Análise, Projeto, Desenvolvimento, Implementação e Avaliação) e a técnica de prototipagem da Engenharia de Software foram utilizados na construção desta aplicação. Utilizou-se a pesquisa avaliativa, por meio de um questionário que foi aplicado aos alunos da disciplina de Inventário Florestal, do curso de graduação em Engenharia Florestal da Universidade Federal do Paraná. Essa avaliação revelou que a percepção dos alunos foi positiva em relação ao software nos seguintes critérios: benefício educacional, facilidade de uso e interesse futuro. O sistema de pontuação do software teve a concordância parcial entre os alunos.
\end{abstract}

Palavras-chave: Engenharia Florestal; Objeto de aprendizagem; Processos de amostragem.

\begin{abstract}
Educational software for teaching forest inventory. Sampling procedures are important in the scope of the forest inventory course in forestry. This study reports the implementation and the use of a learning object, which offers to the student 16 exercises about the sampling techniques. The developed application does not need to be installed and is accessed through the internet. The used data are individually generated for each student and the correction of the exercises is performed automatically. The ADDIE (Analysis, Design, Development, Implementation and Evaluation) model and the prototyping technique of software engineering were used in the construction of this software. Evaluative research was used during the test application, effectuated with students of the Forest Inventory course of the School of Forestry of the Federal University of Paraná. This survey confirmed that the software provoked a positive perception by the students regarding educational benefit, ease of use and appropriate for learning. The scoring system was only partially accepted as good tool for evaluation according to the students' opinion.
\end{abstract}

Keywords: Forestry; Learning object; Sampling procedures.

\section{INTRODUÇÃO}

O inventário florestal é uma importante disciplina para o manejo florestal. Por meio dele, é possível conhecer os recursos florestais em uma determinada área. Segundo Péllico Netto e Brena (1997), o inventário florestal é uma atividade que visa obter informações qualitativas e quantitativas dos recursos florestais existentes em uma área pré-especificada. Por outro lado, de acordo com Sanquetta et al. (2009), esse conceito é genérico o bastante para incluir qualquer tipo de levantamento florestal, mas salienta que a principal característica de um inventário é a sua representatividade amostral e validade estatística. 
Laar e Akça (2007) acrescentam que o objetivo de um inventário florestal é obter informações quantitativas e qualitativas sobre os recursos da floresta e seu ambiente físico, em um ponto específico no tempo, por um custo razoável. Para Queiroz (2012), inventário florestal é o ramo da ciência florestal que visa avaliar as variáveis da floresta e suas inter-relações, assim como dinâmicas de crescimento e sucessão florestal, servindo de base para a formulação de planos de utilização de produtos florestais, manejo sustentado integrado da floresta, bem como alicerçar propostas de planos de desenvolvimento e políticas florestais de caráter regional ou nacional.

Um inventário florestal pode ser classificado segundo seus objetivos, abrangências, formas de obtenção de dados, abordagens da população no tempo e graus de detalhamento dos recursos (PÉLLICO NETTO; BRENA, 1997). Considerando a classificação de acordo com a forma de obtenção de dados, os inventários podem ser do tipo: por enumeração total ou censo, por amostragem e por tabela de produção. A maior parte deles se insere no grupo dos efetuados por amostragem, nos quais é necessário medir apenas alguns indivíduos da população para formar uma amostra, visando otimizar tempo e custo (HUSH et al., 1982; PÉLLICO NETTO; BRENA, 1997; LAAR; AKÇA, 2007; SANQUETTA, et al., 2009).

Segundo Druszcz et al. (2013), as técnicas de amostragem em campo para coleta de informações quantitativas e qualitativas da floresta dificilmente serão abolidas, mesmo levando-se em consideração as inovações tecnológicas, como, por exemplo, a tecnologia LiDAR (light detection and ranging). Contudo, esses autores afirmam também que o custo existente na aplicação dessas técnicas aumenta conforme o nível de precisão e o tempo requeridos.

Os métodos de amostragem se referem à seleção dos indivíduos que participam da unidade amostral, como área fixa, Bitterlich, Prodan, Strand e 3-P. Por outro lado, os processos de amostragem se referem à abordagem do conjunto das unidades amostrais, podendo ser para uma única ocasião, classificados em: aleatório, sistemático ou misto. Ao passo que a categoria dos processos para múltiplas ocasiões pode ser do tipo: independente, com repetição total, dupla e com repetição parcial (PÉLLICO NETTO; BRENA, 1997).

Os conceitos estatísticos envolvidos nos conteúdos dos processos de amostragem são muito importantes para um aluno de engenharia florestal. A resolução n 3 de 2 de fevereiro de 2006 do Conselho Nacional de Educação (BRASIL, 2006), que estabelece as Diretrizes Curriculares Nacionais para o curso de graduação em Engenharia Florestal, determina que a ementa de Inventário Florestal deve fazer parte do núcleo de conteúdos profissionais essenciais.

Com isso, a aplicação de tecnologia da informação no processamento e na coleta de dados dos inventários florestais é uma realidade inegável, em que se faz necessário a aplicação de softwares para otimizar custos e tempo. Alguns exemplos de softwares que podem ser utilizados para auxiliar no processamento do inventário florestal são: Mata Nativa (CIENTEC, 2014), Faça Floresta (INSTITUTO BRASILEIRO DE FLORESTAS, 2014), SifcubCE, SifcubDesktop, Sifcub, Sifprog, Sifplan, SifcadSifquality (TREESOFTWARE, 2013) e C7 LDFP (PROJETO CR CAMPEIRO - UFSM, 2014).

Por outro lado, as tecnologias voltadas para o ensino não evoluíram na mesma velocidade. No ensino superior, e mais especialmente nas engenharias, os conteúdos ministrados possuem uma alta complexidade, com uma teoria bastante extensa. Tais conteúdos normalmente são ministrados por meio de aulas expositivas e resolução de exercícios. Esse quadro complica quando se considera a geração atual de estudantes em meio ao mundo digital de computadores, internet, videogames, telefones celulares, tablets e outros eletrônicos. Assim, simuladores computacionais, conteúdos multimídia e jogos digitais podem ser desenvolvidos para apresentar tópicos de engenharia de modo a superar algumas limitações do formato expositivo (DESHPANDE; HUANG, 2009).

Pensando nessas ferramentas, os objetos de aprendizagem se tornaram um conceito bastante difundido e aceito pelos educadores nas últimas décadas. Segundo Wiley (2000), um objeto de aprendizagem pode ser definido como qualquer recurso digital que possa ser reutilizado para o suporte ao ensino. O Ministério da Educação do Brasil disponibiliza um portal na Internet para busca e catalogação de objetos de aprendizagem nacionais e internacionais que estejam disponíveis de forma gratuita. Uma busca nesse portal revelou que existem 15 objetos de aprendizagem na área de Recursos Florestais e Engenharia Florestal. Foram encontrados quatro vídeos, nove imagens e uma animação, ao passo que nenhum software educacional foi encontrado (BRASIL, 2008).

Desta forma, este trabalho visa apresentar um software educacional desenvolvido no programa de Pós-graduação de Engenharia Florestal da Universidade Federal do Paraná, com o objetivo de auxiliar os alunos dos cursos de graduação e pós-graduação na compreensão do conteúdo dos processos de amostragem da disciplina de Inventário Florestal. Para isso, o software desenvolvido é executado em um browser, acessado pela Internet, onde exercícios relacionados aos processos de 
amostragem são sugeridos e personalizados por aluno, permitindo o uso de planilhas eletrônicas para a realização dos cálculos, correção dos valores inseridos pelo aluno e fornecimento de pontuação por acerto.

\section{MATERIAIS E MÉTODOS}

\section{Metodologia}

Para o desenvolvimento do software educacional, seguiu-se uma abordagem metodológica dupla: $1^{\circ}$ ) construção de material instrucional; $2^{\circ}$ ) técnicas de engenharia de software. A metodologia para construção de material instrucional foi baseada em um modelo de cinco fases, denominado APDIA - Análise, Projeto, Desenvolvimento, Implementação e Avaliação (FOREST, 2014). Segundo Souza et al. (2007), na fase de análise estuda-se as características do aprendiz e da tarefa a ser ensinada; a fase de projeto define a escolha da abordagem instrucional; o material é criado na fase de desenvolvimento; a implementação foca nos aspectos de distribuição e entrega do material; e na fase de avaliação verifica se o material atingiu os objetivos. A construção do software educacional apresentado neste artigo seguiu as seguintes etapas de desenvolvimento:

- Análise: Foi definido que o software abordaria a disciplina de inventário florestal e, mais especificamente, os exercícios práticos sobre os processos de amostragem (PÉLLICO NETTO; BRENA, 1997).

- Projeto: Nessa fase, as tecnologias a serem utilizadas no software foram definidas. Concernente à tecnologia, foram realizados testes para definir a utilização das bibliotecas mais apropriadas para o software.

- Desenvolvimento: Nessa fase, utilizou-se a técnica de prototipagem (PRESSMAN, 2006). O primeiro protótipo gerado foi uma biblioteca orientada a objetos para cálculos estatísticos dos processos de amostragem florestal. A validação dessa biblioteca ocorreu com a resolução automática dos exercícios e a conferência dos resultados. Os protótipos seguintes tiveram a intenção de validar as interações com os usuários (alunos) e a geração automatizada de dados pelo sistema. Portanto, essa fase de construção do software se deu por meio de iterações, em que o objetivo de cada iteração era validar o protótipo com um autor do livro de texto e o orientador desta pesquisa.

- Implantação: Depois de construído, o software foi implantado em uma máquina servidora na Universidade Federal do Paraná e distribuído de forma on-line, não havendo a necessidade de instalação.

- Avaliação: Nessa fase, foi realizada uma pesquisa avaliativa, baseada em um questionário aplicado ao $5^{\circ}$ período do curso de Engenharia Florestal da UFPR no primeiro semestre de 2014. Em um encontro, essa turma foi exposta ao software por meio de uma demonstração. No outro encontro, foi solicitado aos alunos resolver o desafio 6 do software em um laboratório com máquinas individuais. Por último, foi solicitado à turma responder o questionário. A prática de avaliar um objeto de aprendizagem por meio da aplicação de questionários não é incomum, podendo ser observada em alguns trabalhos científicos (KAY; KNAACK, 2007).

Para a avaliação do software, utilizou-se a pesquisa avaliativa por meio de um questionário com questões objetivas e respostas abertas (Tabela 1), com a estrutura adaptada de Kay e Knaack (2007) e Nugent et al. (2006). Nas questões objetivas, cada aluno marcou uma das seguintes opções: discordo, discordo parcialmente, neutro, concordo parcialmente e concordo. Os resultados foram avaliados por meio da atribuição dos seguintes pesos: 1 para discordo, 2 para discordo parcialmente, 3 para neutro, 4 para concordo parcialmente e 5 para concordo. Com base nesses pesos, foram aplicadas a média e o desvio padrão, a fim de verificar o nível de concordância média de cada questão e a dispersão que cada uma gerou nas respostas, enquanto as questões abertas foram utilizadas para avaliação qualitativa do objeto de aprendizagem.

\section{Tecnologias}

Para a programação do núcleo do software, foi utilizada a linguagem Java versão 7, que segue o paradigma orientado a objetos e possui uma biblioteca de programação bastante ampla. A Oracle (2014), define Java como uma linguagem de programação e uma plataforma de desenvolvimento. Essa 
linguagem foi escolhida por ser amplamente utilizada no mercado e também na academia. Segundo o índice Tiobe, que mede a popularidade das linguagens de programação, Java é a segunda em popularidade no mês de março de 2014, com 16,4\% (TIOBE, 2014). Entretanto, nos últimos 12 anos, vem alternando a primeira e segunda posição em popularidade. Outra justificativa para a escolha da linguagem é o seu suporte nativo para a construção de aplicações para Internet.

Tabela 1. Questionário da avaliação

\begin{tabular}{|c|c|c|}
\hline No. & Tipo & Questão \\
\hline 1 & Objetiva & O Simulador Florestal agrega valor à disciplina de Inventário Florestal. \\
\hline 2 & Objetiva & O Simulador Florestal possibilita outra estratégia de aprendizado. \\
\hline 3 & Objetiva & $\begin{array}{l}\text { Eu sinto que o Simulador Florestal pode beneficiar o entendimento sobre os cálculos } \\
\text { estatísticos referentes aos processos de amostragem. }\end{array}$ \\
\hline 4 & Objetiva & O software Simulador Florestal é de fácil operação. \\
\hline 5 & Objetiva & $\begin{array}{l}\text { Outros exercícios ao longo do curso poderiam ser apresentados por um objeto de } \\
\text { aprendizagem semelhante a este. }\end{array}$ \\
\hline 6 & Objetiva & $\begin{array}{l}\text { De um modo geral o Simulador Florestal é um bom complemento ao conteúdo } \\
\text { ministrado em sala de aula. }\end{array}$ \\
\hline 7 & Objetiva & $\begin{array}{l}\text { O sistema de pontuação do software me incentivou a pensar melhor na solução dos } \\
\text { problemas propostos. }\end{array}$ \\
\hline 8 & Objetiva & A correção dos exercícios em tempo real me ajudou na solução dos problemas. \\
\hline 9 & Objetiva & Eu estou interessado em utilizar o Simulador Florestal novamente. \\
\hline 10 & Objetiva & $\begin{array}{l}\text { De um modo geral, como você avalia o Simulador Florestal. (Péssimo, Fraco, Regular, } \\
\text { Bom e Excelente) }\end{array}$ \\
\hline 11 & Aberta & O que você gostou no Simulador Florestal? \\
\hline 12 & Aberta & O que você não gostou no Simulador Florestal apresentado? \\
\hline 13 & Aberta & Você tem alguma sugestão sobre o Simulador Florestal? \\
\hline
\end{tabular}

No desenvolvimento da interface gráfica, foi utilizada a linguagem JavaScript interpretada pelo navegador da Internet, em conjunto com a biblioteca ExtJs versão 3.4 (SENCHA, 2014), o que possibilitou o desenvolvimento de uma interface interativa e disponibilizada via navegador da Internet, sem a necessidade de instalação de softwares adicionais. Em complemento, foram utilizadas algumas bibliotecas que facilitaram e aceleraram o desenvolvimento do núcleo do software, tais como: Apache Commons Math 3.3.0 (biblioteca que contém componentes matemáticos e estatísticos), Apache Commons Bean Utils 1.8.0, Apache Commons Codec 1.5, Apache Commons Collections 3.2.1, Apache Commons Lang 2.5, Apache Commons Logging 1.1.1, EzMorph 1.0.6 e Apache Poi 3.9 (THE APACHE SOFTWARE FOUNDATION, 2013; EZMorth, 2014; THE APACHE POI PROJECT, 2014).

O armazenamento de dados foi suportado pelo software MySQL versão 5.6 (ORACLE, 2014), sendo um sistema gerenciador de banco de dados relacional e que utiliza a linguagem SQL (Structured Query Language) para manipulação dos dados. Como o software desenvolvido está disponível na Internet, foi necessário utilizar o servidor para páginas dinâmicas Tomcat (versão 7) que suporta a linguagem Java. A Figura 1 ilustra os componentes de tecnologia utilizados e seus relacionamentos com o hardware. O browser, a biblioteca ExtJs e a linguagem JavaScript executam na máquina cliente (aluno), ao passo que o banco de dados (MySQL), o servidor de internet (Apache Tomcat), as bibliotecas (Apache Commons) e os componentes escritos na linguagem Java executam na máquina servidora.

\section{Dados}

O objeto de aprendizagem desenvolvido teve como base teórica os 16 processos de amostragem apresentados no livro texto Inventário Florestal de Péllico Netto e Brena (1997), tais como: parâmetros da população, por estratificação, por faixa de tamanho igual, por faixa de tamanho diferente e por unidade primária; e amostragens aleatória simples, aleatória simples com unidades amostrais de 
tamanhos diferentes, estratificada, sistemática em dois estágios, em dois estágios, em conglomerados, em múltiplos inícios aleatórios, em múltiplas ocasiões com amostras independentes, em múltiplas ocasiões por amostragem dupla e em múltiplas ocasiões com repetição parcial. Por outro lado, esses dados serviram como base para que o sistema gerasse automaticamente subconjuntos individuais por aluno. Para isso, foi utilizada a biblioteca de programação Apache Commons Math 3.3.0., a qual estima uma função densidade de probabilidade por meio do método do núcleo-estimador variável (THE APACHE SOFTWARE FOUNDATION, 2013).

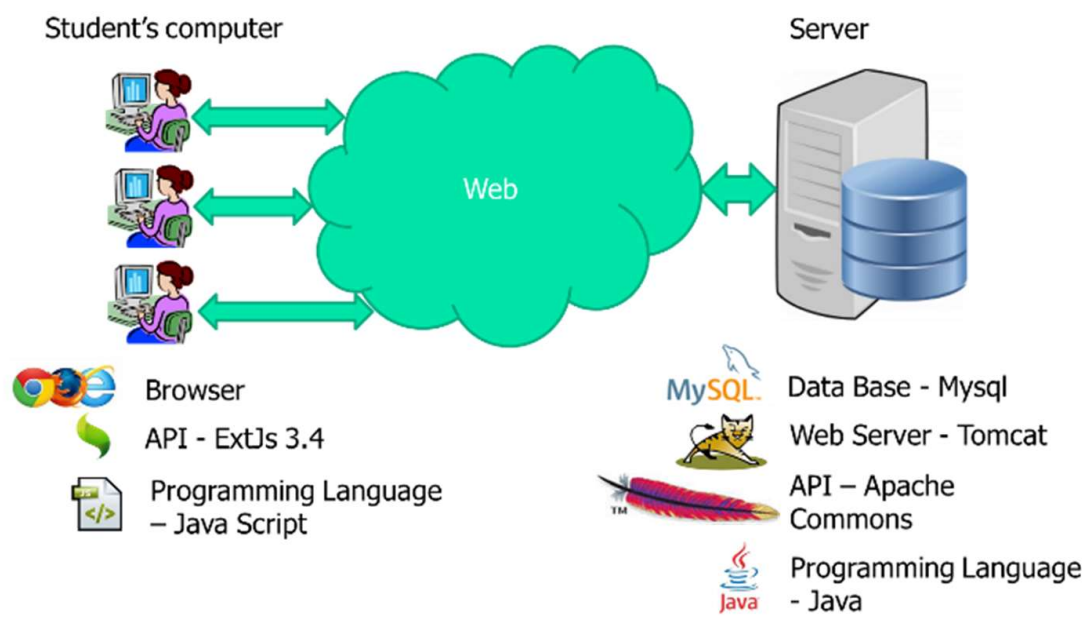

Figura 1. Diagrama simplificado de componentes do software.

\section{RESULTADOS}

\section{Apresentação do sistema}

O sistema de aprendizagem desenvolvido possui um esquema básico de funcionamento (Figura 2). O professor deve fornecer os conceitos teóricos sobre os processos de amostragem, pois o software não os contém disponibilizados para a utilização em inventários florestais. O aluno se cadastra ao sistema e tem acesso ao conjunto de exercícios propostos. Os dados e as estruturas das unidades amostrais são criados pelo sistema de maneira aleatória por meio de um gerador e, como consequência, os alunos terão exercícios personalizados que podem ser exportados para uma planilha eletrônica e, assim, efetuar os cálculos necessários, retornar ao sistema e conferir os valores obtidos, informando ao aluno quando o seu cálculo está incorreto.

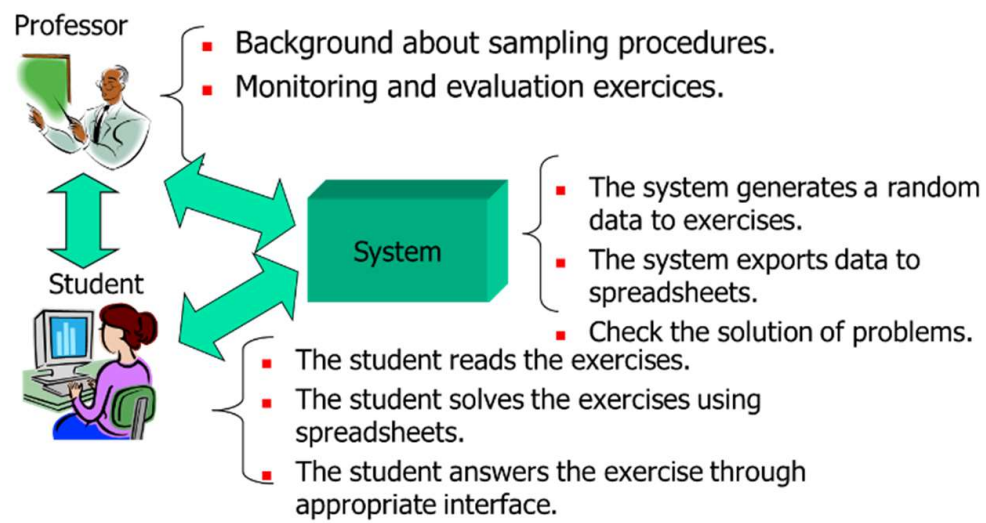

Figura 2. Esquema básico de funcionamento.

As interações entre o sistema desenvolvido e o aluno podem ser ilustradas por meio de um fluxograma básico (Figura 3), em que a criação do login é o primeiro passo. O segundo passo (executado pelo sistema) é a criação dos 16 desafios sobre os processos de amostragem em um 
inventário florestal com dados aleatórios e individualizados. No terceiro passo, o aluno efetua o login no sistema e tem acesso aos exercícios propostos. O quarto passo é a resolução dos exercícios pelo aluno, que é corrigido pelo sistema no quinto passo, sendo repetidos múltiplas vezes até que o aluno tenha completado um desafio e possa iniciar a resolução do próximo.

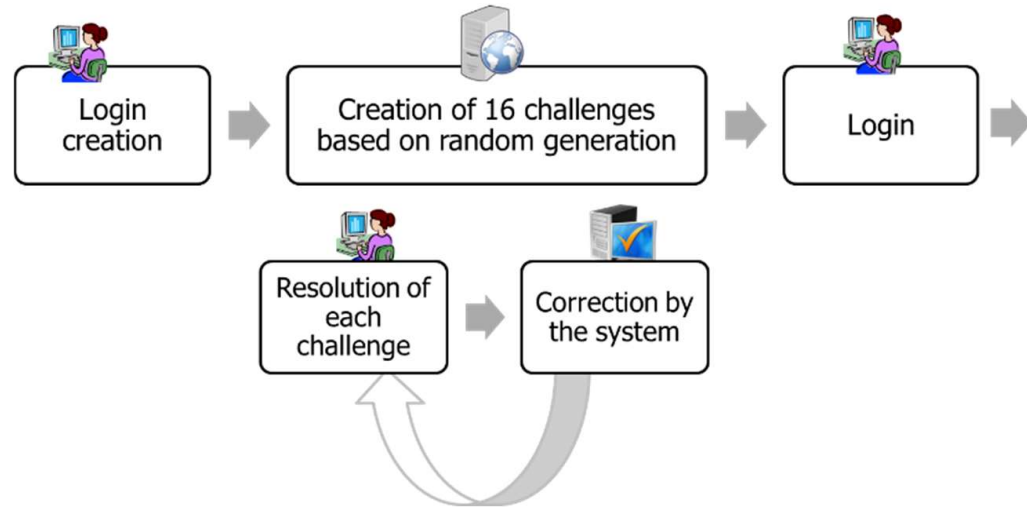

Figura 3. Fluxograma de funcionamento.

Cada desafio é composto por um conjunto de questões que deve ser resolvido pelo aluno. A Tabela 2 apresenta a quantidade de questões para cada desafio e o total de questões existentes no sistema.

Tabela 2. Desafios e questões

\begin{tabular}{ccc}
\hline Número & Nome do Desafio & Questões \\
\hline 1 & Parâmetros da População & 5 \\
2 & Parâmetros da População Estratificada & 5 \\
3 & Parâmetros da População por Faixa de Tamanho lgual & 5 \\
4 & Parâmetros da População por Faixa de Tamanho Diferente & 5 \\
5 & Parâmetros da População por Unidade Primária & 3 \\
6 & Amostragem Aleatória Simples & 18 \\
7 & Amostragem Aleatória Simples - Unidades Amostrais de Tamanhos Diferentes & 16 \\
8 & Amostragem Estratificada & 19 \\
9 & Amostragem Sistemática em Dois Estágios & 14 \\
10 & Amostragem em Dois Estágios & 20 \\
11 & Amostragem em Conglomerados & 20 \\
12 & Amostragem Sistemática com Múltiplos Inícios Aleatórios & 20 \\
13 & Amostragem em Múltiplas Ocasiões - Amostras Independentes & 28 \\
14 & Amostragem em Múltiplas Ocasiões - Amostras Com Repetição Total & 28 \\
15 & Amostragem em Múltiplas Ocasiões - Amostragem Dupla & 36 \\
16 & Amostragem em Múltiplas Ocasiões - Repetição Parcial & 36 \\
\hline
\end{tabular}

\section{Principais funcionalidades do sistema}

Como o software está disponível na Internet, basta ao aluno digitar a URL (Uniform Resource Locator) do sistema em um browser para que tenha acesso à tela de login (Figura 4a) preenchendo os dados de matrícula, senha. Também é possível criar um novo usuário por meio do botão no canto inferior esquerdo. Se optar por criar um novo usuário, então a tela ilustrada na Figura 4b será mostrada. Quando um novo usuário é criado, o sistema inclui os 16 desafios para ele. No contexto desse software, desafios se referem aos exercícios que o aluno deve resolver. 


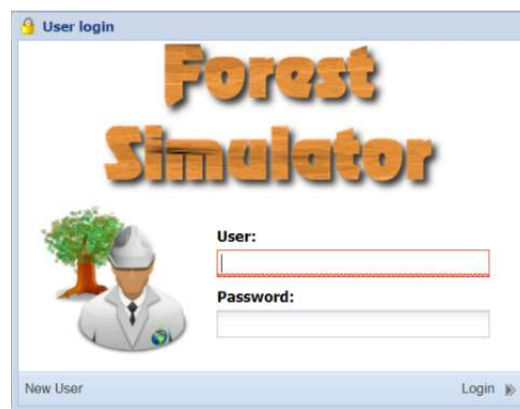

(a)

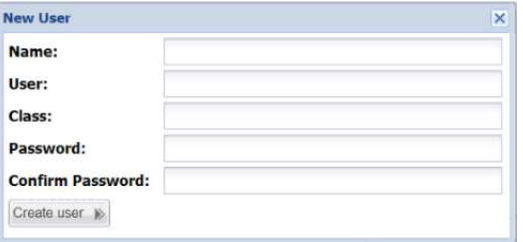

(b)

Figura 4. (a) Tela de login (b) Tela de criação de novo usuário.

Os desafios criados pelo software são exercícios que cobrem 16 processos de amostragem. Após o login, o aluno é direcionado para uma tela que apresenta o estado dos desafios (Figura 5).

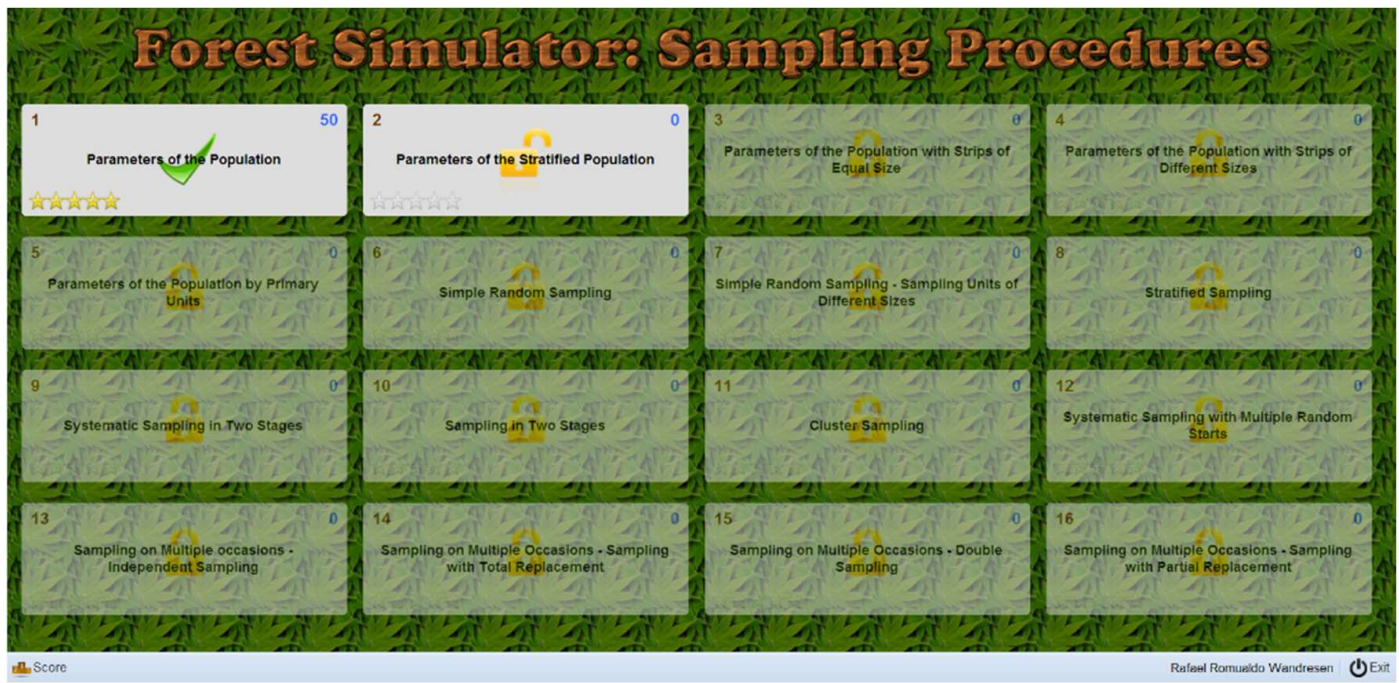

Figura 5. Tela inicial.

Os exercícios podem assumir quatro estados indicados pelos ícones e pela transparência do quadro do desafio. No exemplo da Figura 5, o desafio 1 (Parâmetros da População) foi finalizado, ao passo que o desafio 2 (Parâmetros da População Estratificada) está disponível, mas ainda não iniciado, e os desafios 3 a 16 estão bloqueados. Assim, o desafio 3 se tornará disponível quando o aluno acertar todas as questões do desafio 2. Quando um desafio é iniciado pelo aluno, no qual pelo menos uma resposta foi fornecida para o sistema, o estado do desafio é indicado pelo ícone ilustrado na Figura 6.

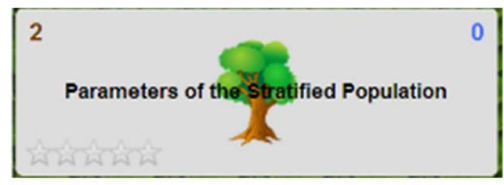

Figura 6. Desafio iniciado.

A pontuação obtida é observada no canto superior direito de cada desafio e, abaixo do nome de cada, aparecem as estrelas obtidas referentes a pontuação relativa. No exemplo da Figura 5, 50 pontos com cinco estrelas foram obtidos no desafio 1, com percentual de acerto entre 80 e $100 \%$. Cada um dos 16 desafios possui telas específicas e, para ilustrar o funcionamento do software, pode-se separar os desafios em grupos com comportamentos similares. A classificação demonstrada na Tabela 3 não tem a intenção de propor uma taxonomia para os processos de amostragem, mas sim de organizar a apresentação do software neste artigo. 
Tabela 3. Organização dos processos de amostragem

Grupo Processos de Amostragem

Grupo 1 Parâmetros da população, parâmetros da população estratificada, parâmetros da população por faixa de tamanho igual, parâmetros da população por faixa de tamanho diferente e parâmetros da população por unidade primária.

Grupo 2 Amostragem aleatória simples, amostragem aleatória simples com unidades amostrais de tamanhos diferentes, amostragem estratificada e amostragem sistemática em dois estágios.

Grupo 3 Amostragem em dois estágios, amostragem em conglomerados e amostragem sistemática com múltiplos inícios aleatórios.

Grupo 4 Amostragem em múltiplas ocasiões com amostras independentes, amostragem em múltiplas ocasiões por amostragem dupla e amostragem em múltiplas ocasiões com repetição parcial.

Nos desafios do Grupo 1, o aluno deve passar pelos seguintes passos:

1. A primeira tela desses desafios apresenta as unidades amostrais de uma população de Pinus sp. organizada em uma tabela com unidades primárias e secundárias, com valores em volume de madeira por hectare (Figura 7). $\mathrm{O}$ aluno pode obter uma planilha em formato .xls para realizar os cálculos referentes a cada processo. Clicando em "Responder", o aluno irá para o segundo passo do desafio.

Ainda, pode-se observar na Figura 7 que a área da esquerda da tela é reservada para instruções, no qual o aluno obtém informações que podem ser utilizadas para responder às questões e também orientações para uso do software. Todas as telas dos desafios possuem essa área de instruções que é específica para cada uma.

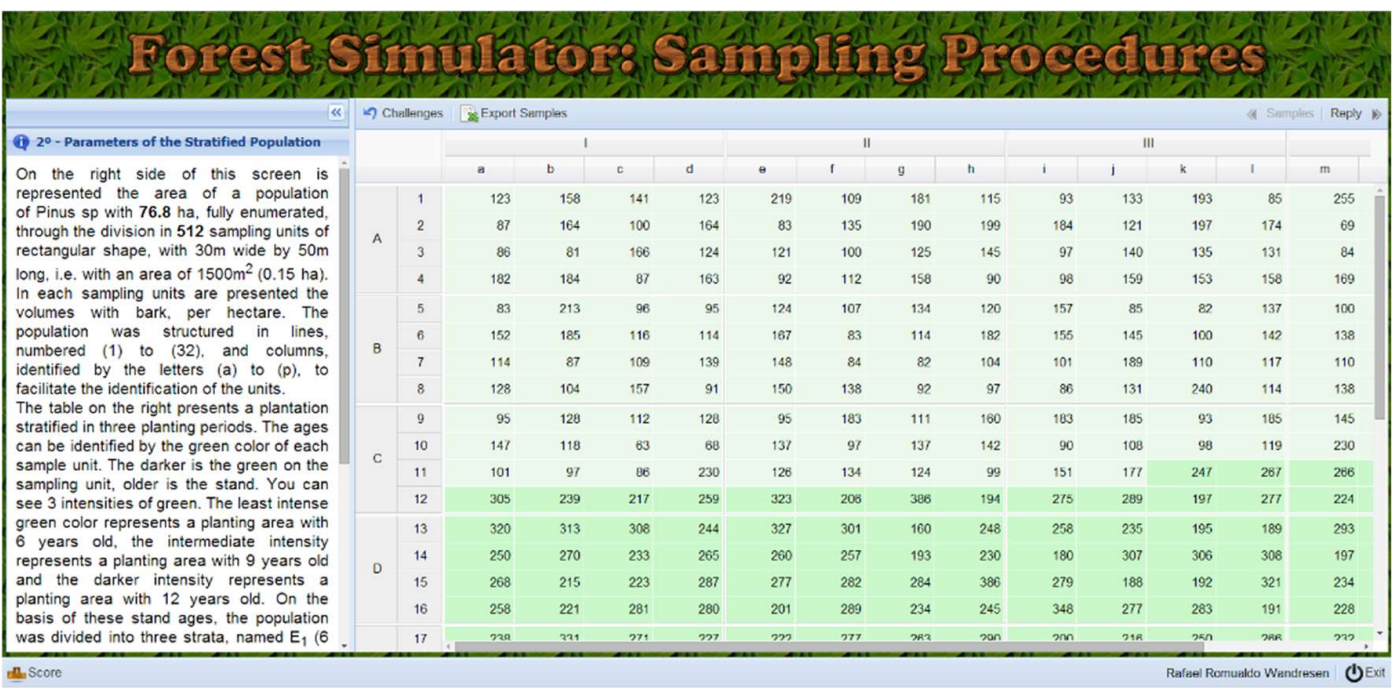

Figura 7. Passo 1 do desafio 2 - Parâmetros da população estratificada.

2. No passo 2, o aluno deve responder às questões do desafio referentes aos parâmetros da população representada pelas unidades amostrais. Na Figura 8 pode-se observar que o aluno respondeu aos parâmetros dos estratos e à média estratificada corretamente, por esse motivo, os campos estão em verde, ao passo que o parâmetro variância estratificada foi respondido com erro, portanto o sistema apresenta na cor vermelha.

Para responder cada um dos parâmetros, o aluno deve clicar no ícone ao lado da caixa de texto, ou então no botão "Responder" correspondentes, ou, ainda, no botão "Responder Todas". Ao fazer isso, o sistema avalia se a resposta inserida pelo aluno está correta ou não, informando-o pelas cores verde (caso correto) ou vermelha (caso errado). Esse comportamento é válido para todos os outros desafios. 


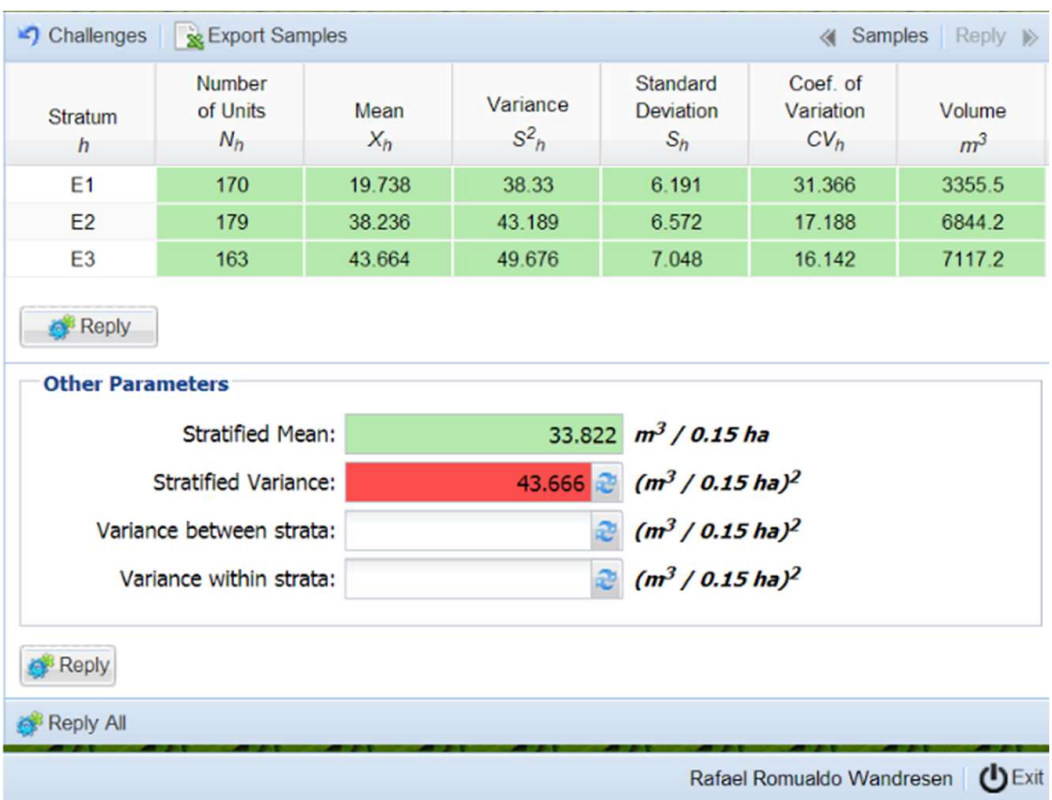

Figura 8. Passo 2 do desafio 2 - Parâmetros da população estratificada.

Os desafios do Grupo 2 são compostos pelos seguintes passos:

1. No primeiro passo, o sistema apresenta uma tabela sem valores, que representa uma área de uma população de Pinus sp. organizada em unidades primárias e secundárias (Figura 9). Assim, o aluno deve selecionar as unidades amostrais do inventário piloto clicando sobre as células, ou colunas da tabela, dependendo do desafio. No exemplo ilustrado, o aluno escolheu as seguintes unidades amostrais: 4-c, 3-e, 9-b, 7-e e 7-h. Os valores de volume de madeira por hectare são revelados quando se interage com a tabela. Depois de selecionadas, o aluno deve clicar em "Próximo".

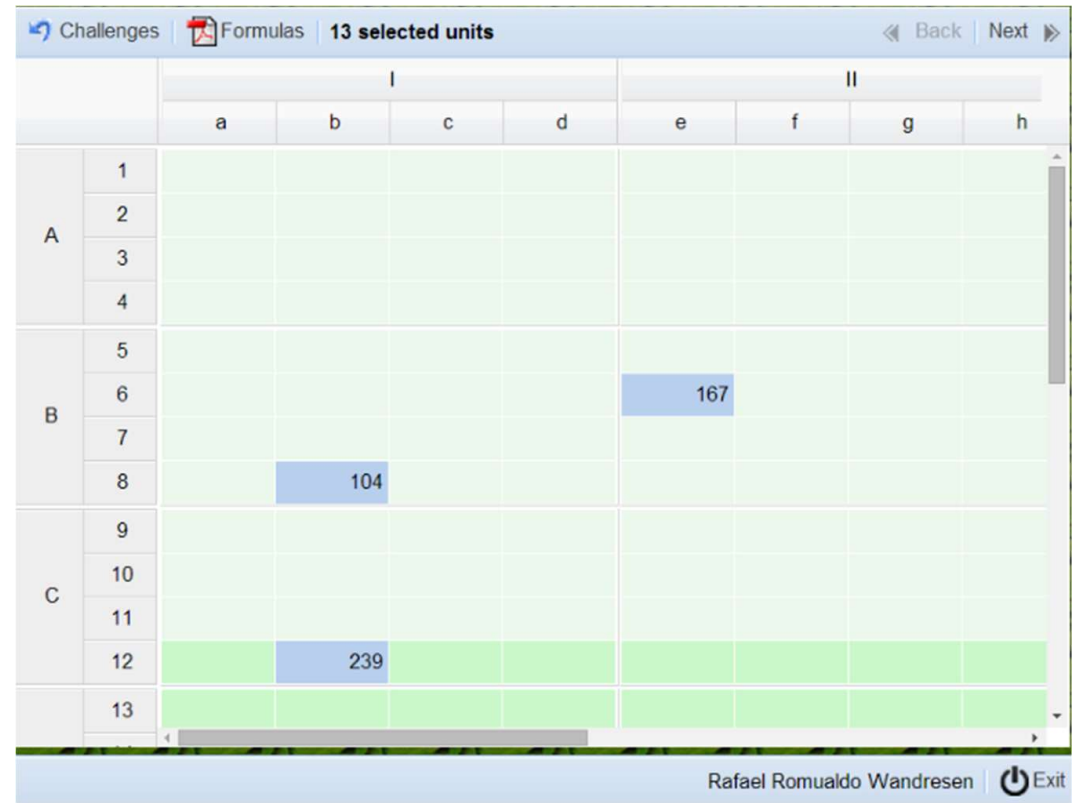

Figura 1. Passo 1 do desafio 6 - Amostragem Aleatória Simples.

2. Nesta etapa, o aluno visualiza as unidades amostrais escolhidas para o inventário piloto (Figura 10). Ele deve copiar e colar a tabela apresentada para uma planilha, com o objetivo de realizar os cálculos do inventário piloto. Clicando em "Próximo", será direcionado ao passo seguinte. 


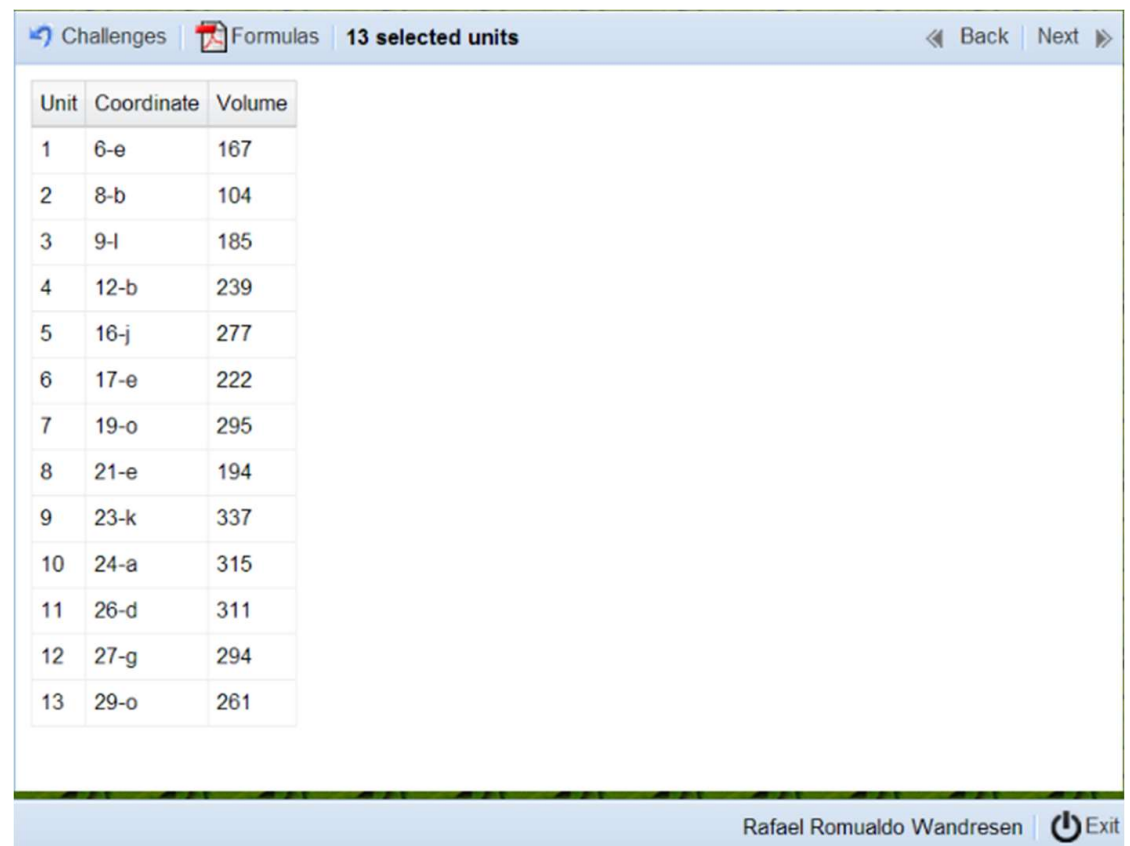

Figura 102. Passo 2 do desafio 6 - Amostragem Aleatória Simples.

3. Neste passo, o aluno deve calcular as estatísticas do inventário piloto com base nas amostras escolhidas. Após calcular corretamente, o sistema direciona o aluno para acrescentar as unidades amostrais de acordo com o cálculo da intensidade amostral. Isso é feito na mesma tela demonstrada no passo 1 (Figura 9). No exemplo ilustrado (Figura 11), foram selecionadas cinco unidades amostrais, cuja intensidade de amostragem foi de 28 unidades amostrais. Por esse motivo, ao clicar em "Próximo", o sistema apresentará a mensagem ilustrada na Figura 11b e direcionará o aluno para a tela da Figura 9, visando acrescentar as unidades amostrais faltantes para o inventário definitivo.

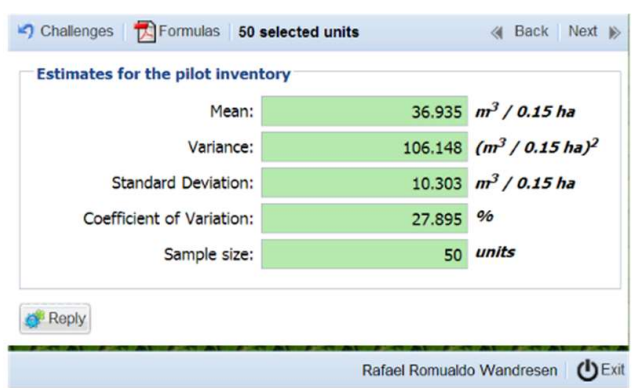

(a)

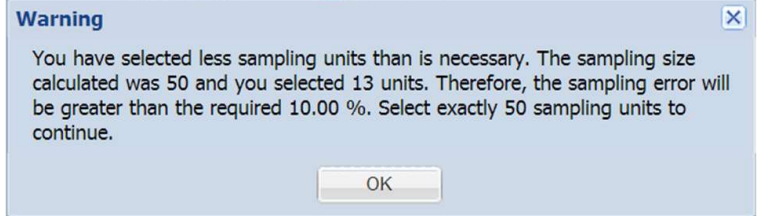

(b)

Figura 113. (a) Passo 3 do desafio 6 - Amostragem Aleatória Simples; (b) Mensagem do sistema.

4. No último passo deste grupo de desafios, o aluno deve inserir as estatísticas para o inventário definitivo. As tabelas com as amostras do inventário definitivo são obtidas do mesmo modo que foi demonstrado no passo 2 (Figura 10). O formulário ilustrado pela Figura 12 apresenta um exemplo das estatísticas do inventário definitivo que foram calculadas pelo aluno e corrigidas pelo sistema, finalizando o desafio. 


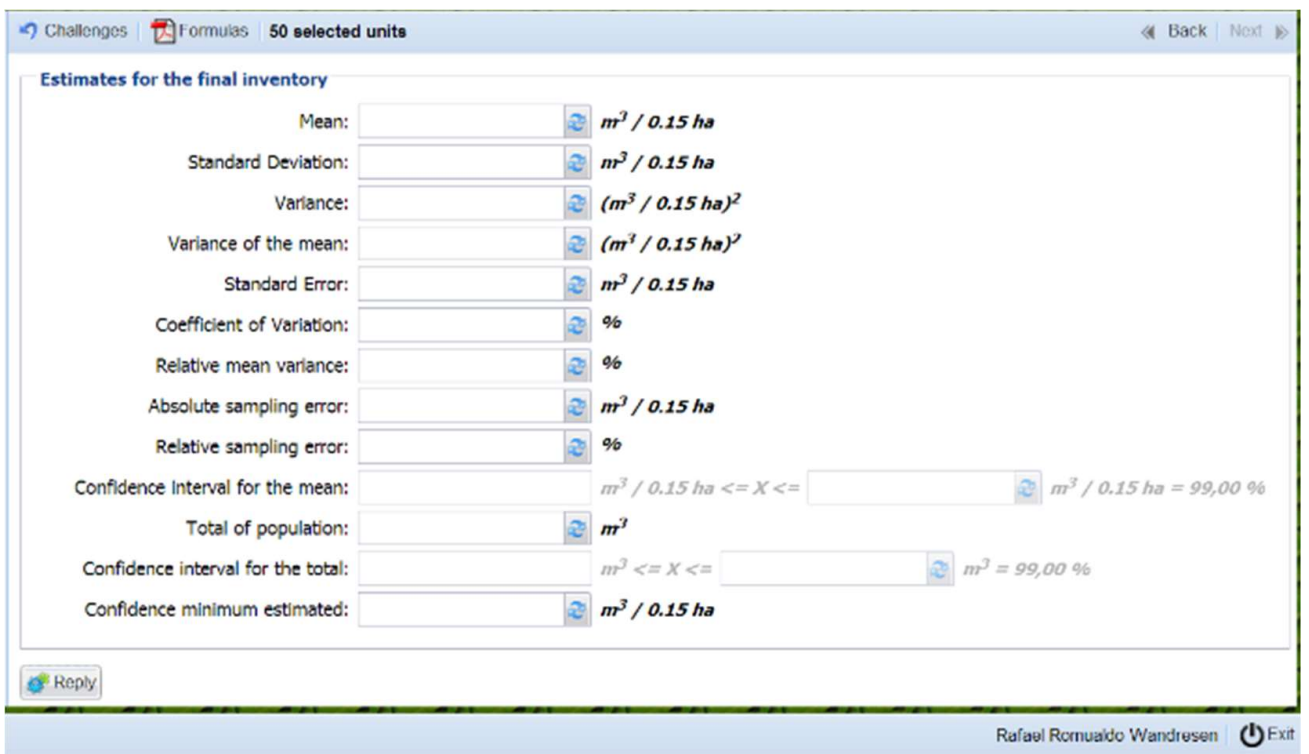

Figura 4. Passo 4 do desafio 6 - Amostragem Aleatória Simples.

O Grupo 3 possui os seguintes passos:

1. As unidades amostrais são pré-selecionadas pelo sistema. Isso indica que a primeira tela apresenta um conjunto estruturadas de acordo com o tipo de amostragem (Figura 13). Por outro lado, a estrutura tem como padrão a separação em unidades primárias e secundárias, em que as unidades secundárias sempre pertencem à uma primária e todas as unidades primárias possuem o mesmo número de secundárias.

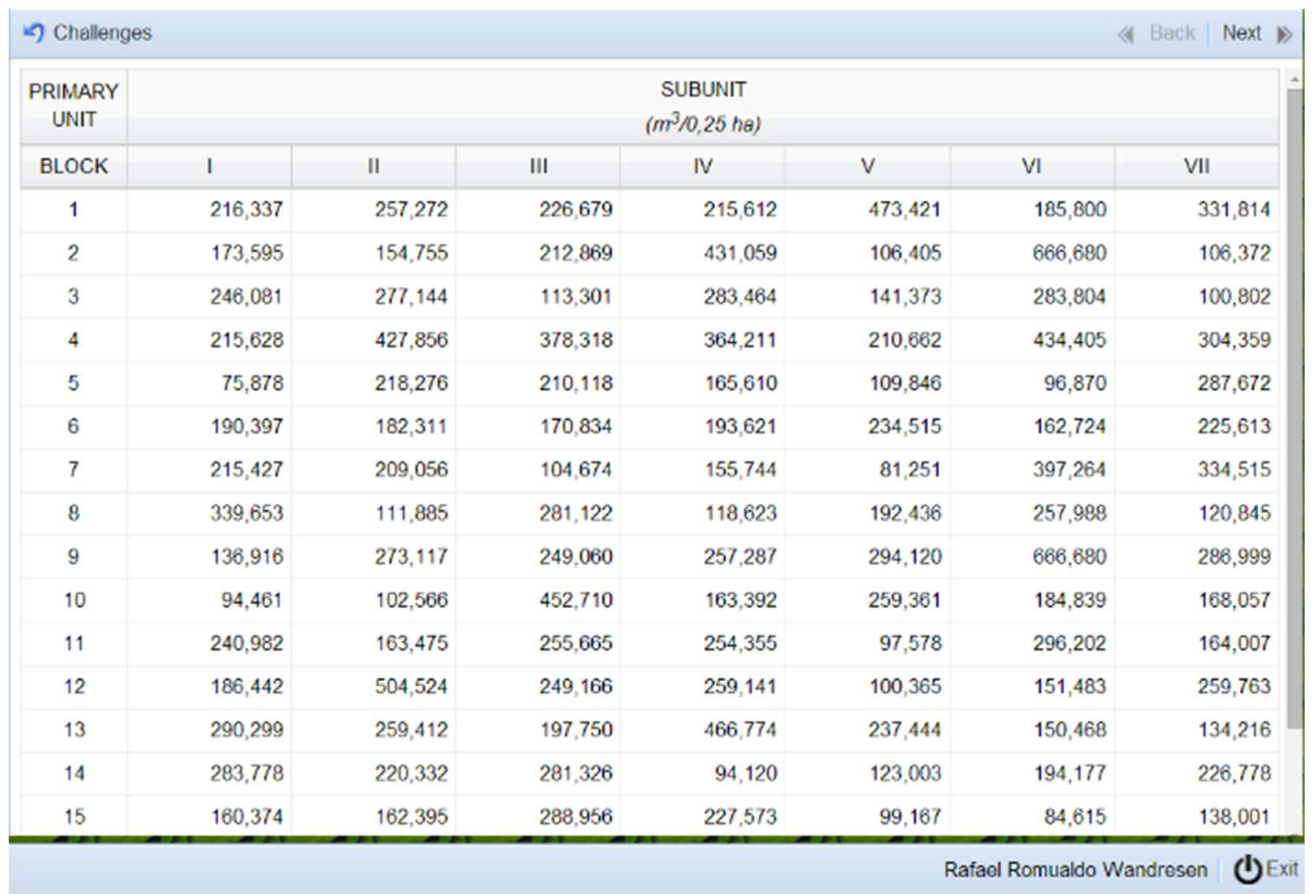

Figura 5. Passo 1 do desafio 10 - Amostragem em Dois Estágios.

2. Da mesma forma que nos desafios do Grupo 2, neste conjunto de desafios o aluno deve calcular as estatísticas para o inventário piloto no segundo passo, acrescentando as estatísticas por 
unidade primária (Figura 14).

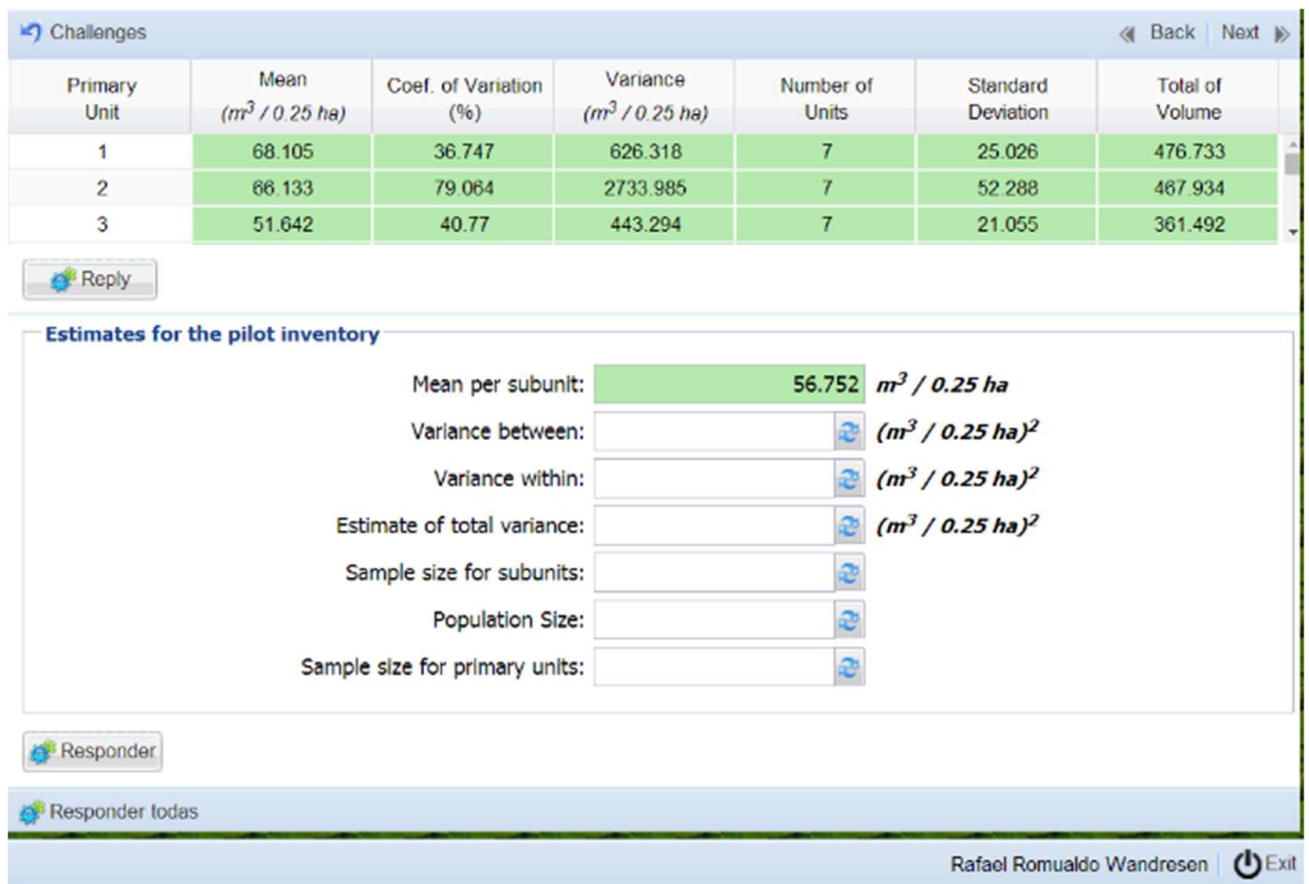

Figura 14. Passo 2 do desafio 10 - Amostragem em Dois Estágios.

3. No terceiro passo, o sistema mostra ao aluno uma tela semelhante à ilustrada na Figura 13 acrescentando as unidades primárias necessárias ao inventário definitivo. Nesse exemplo, o inventário piloto é formado por 18 unidades primárias (Figura 13).

A intensidade amostral calculada resultou em 21 unidades (Figura 14). Portanto, o sistema apresentará uma tabela com as 18 unidades primárias anteriores acrescentando três para formar as 21 unidades do inventário definitivo. O número de unidades secundárias permaneceu o mesmo, pois a intensidade calculada (Figura 14) é menor do que a do inventário piloto (Figura 13).

4. No quarto passo, o aluno deve calcular as estatísticas para o inventário definitivo. Neste exemplo, ele irá calcular as estatísticas baseado em uma amostra de 21 unidades primárias, com 7 unidades secundárias. A tela apresentada pelo sistema é semelhante à ilustrada na Figura 14.

Nos desafios do Grupo 4, dois passos são apresentados:

1. No primeiro, uma tabela representando duas medições em ocasiões diferentes é mostrada em metros cúbicos por hectare. No exemplo da Figura 15, o sistema sorteia 45 unidades amostrais na primeira ocasião e simula um crescimento para segunda, formando as unidades amostrais permanentes.

\begin{tabular}{|c|c|c|}
\hline \multicolumn{2}{|l|}{ C. Challenges } & \multicolumn{2}{|c|}{$\langle$ Samples } & Reply $\gg$ \\
\hline Unit Number & $1^{\text {ST }}$ Occasion & $2^{\text {ND }}$ Occasion \\
\hline 1 & 127,937 & 175,697 \\
\hline 2 & 140,233 & 199,024 \\
\hline 3 & 137,725 & 194,174 \\
\hline 4 & 127,251 & 162,017 \\
\hline 5 & 171,985 & 263,699 \\
\hline
\end{tabular}

Figura 15. Passo 1 do desafio 14 - Amostragem em Múltiplas Ocasiões com Repetição Total. 
2. No segundo passo, o aluno deve calcular as estatísticas para a primeira e segunda ocasiões, bem como para o crescimento e a mudança. A Figura 16 ilustra a tela com os respectivos campos que devem ser respondidos, em que a segunda ocasião foi suprimida por possuir os mesmos campos da primeira.

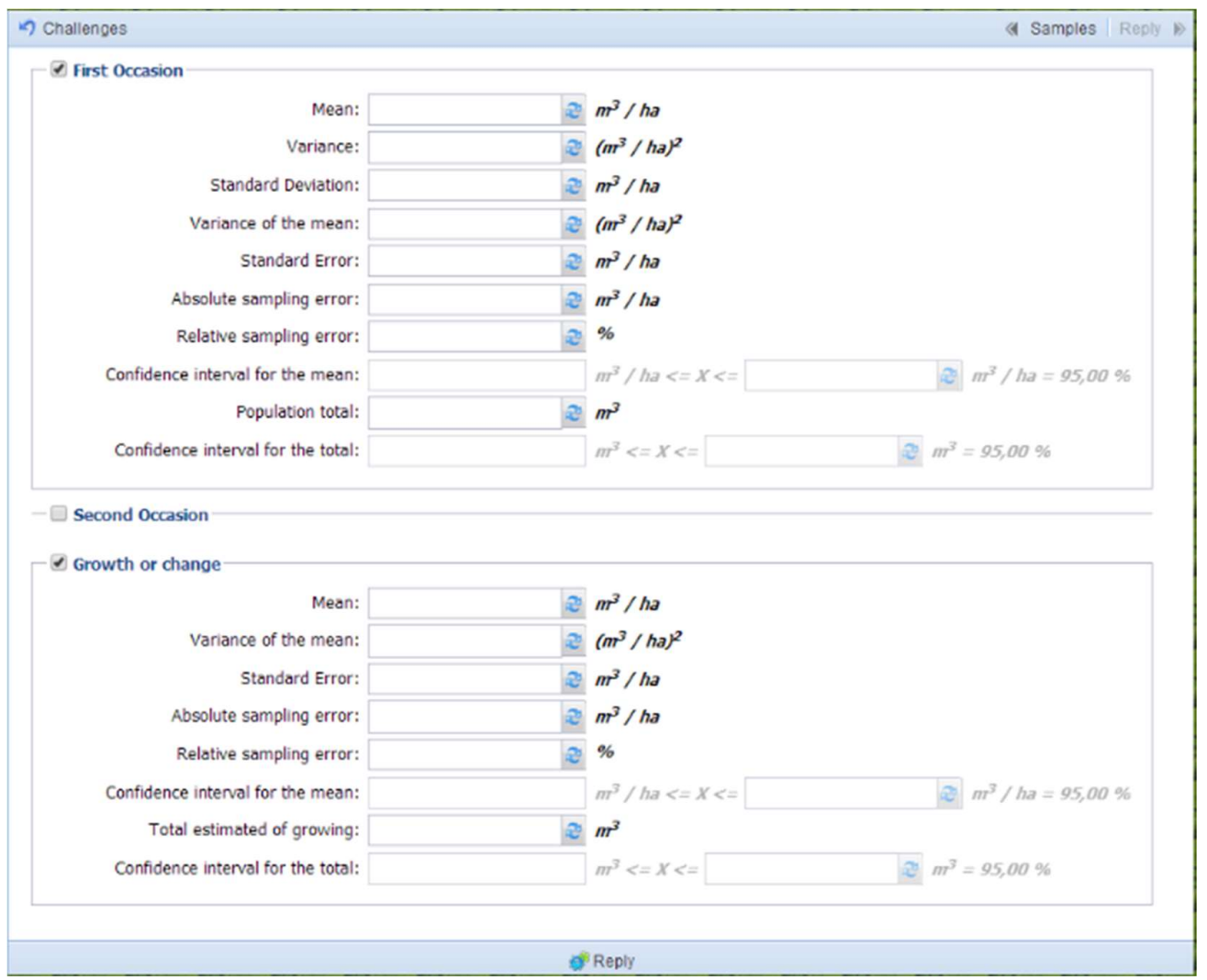

Figura 16. Passo 2 do desafio 14 - Amostragem em Múltiplas Ocasiões com Repetição Total.

\section{Avaliação do software}

A avaliação do software foi realizada com uma turma do quinto semestre do curso de graduação de Engenharia Florestal da Universidade Federal do Paraná. O questionário ilustrado na Tabela 4 foi respondido por 23 alunos após o uso do software no laboratório de informática.

\section{Discussão}

As questões 1, 2, 3 e 6 procuraram avaliar a percepção dos alunos quanto ao benefício educacional que o software proporciona. Pode-se observar, pela média obtida nas respostas, que os alunos concordam com os benefícios apresentados. Além disso, a facilidade de uso do software foi avaliada pelas questões 4 e 8 , em que os alunos concordaram que o software é de fácil operação e que os auxilia na solução dos problemas.

A questão 7 , que avalia o sistema de pontuação, ficou com a menor média entre os quesitos avaliados. Sua tendência foi para uma concordância parcial e gerou a maior discrepância entre as avaliações dos alunos, observada pelo desvio padrão das respostas. Uma hipótese é o fato de o sistema fornecer um relatório comparando o desempenho dos alunos no jogo. Outra hipótese é o fato do sistema penalizar o aluno que insere valores errados muitas vezes no sistema.

As questões 5 e 9 avaliaram o nível de interesse dos alunos para utilizar esse ou outros recursos similares. Nesse grupo, as respostas revelaram que eles têm interesse nessa abordagem como complemento à aprendizagem, ao passo que a questão 10 revelou que o software avaliado teve uma percepção positiva entre os alunos. 
Tabela 4. Resultados da avaliação $(n=23)$

\begin{tabular}{|c|c|c|c|}
\hline No. & Questão & Média & DP \\
\hline 1 & O Simulador Florestal agrega valor à disciplina de Inventário Florestal? & 4,96 & 0,21 \\
\hline 2 & O Simulador Florestal possibilita outra estratégia de aprendizado? & 4,74 & 0,54 \\
\hline 3 & $\begin{array}{l}\text { Eu sinto que o Simulador Florestal pode beneficiar o entendimento sobre os cálculos } \\
\text { estatísticos referentes aos processos de amostragem? }\end{array}$ & 4,91 & 0,29 \\
\hline 4 & O software Simulador Florestal é de fácil operação? & 4,78 & 0,52 \\
\hline 5 & $\begin{array}{c}\text { Outros exercícios ao longo do curso poderiam ser apresentados por um objeto de } \\
\text { aprendizagem semelhante a este? }\end{array}$ & 4,48 & 0,67 \\
\hline 6 & $\begin{array}{l}\text { De modo geral, o Simulador Florestal é um bom complemento ao conteúdo ministrado } \\
\text { em sala de aula? }\end{array}$ & 4,78 & 0,42 \\
\hline 7 & $\begin{array}{c}\text { O sistema de pontuação do software me incentivou a pensar melhor na solução dos } \\
\text { problemas propostos? }\end{array}$ & 4,00 & 1,21 \\
\hline 8 & A correção dos exercícios em tempo real me ajudou na solução dos problemas? & 4,96 & 0,21 \\
\hline 9 & Eu estou interessado em utilizar o Simulador Florestal novamente? & 4,87 & 0,46 \\
\hline 10 & $\begin{array}{c}\text { De modo geral, como você avalia o Simulador Florestal (Péssimo, Fraco, Regular, Bom } \\
\text { e Excelente)? }\end{array}$ & 4,61 & 0,50 \\
\hline
\end{tabular}

Este trabalho seguiu a metodologia de Nugent et al. (2006), os quais avaliaram softwares educacionais para o ensino do paradigma de orientação à objetos para Ciência de Computação, verificando os aspectos de facilidade de uso, benefícios educacionais, aplicações futuras da ferramenta e aspectos gerais. Com isso, os resultados obtidos por esses autores foram similares aos obtidos neste estudo, cujos estudantes consideraram que o software era simples de utilizar e adicionava valor à disciplina.

No trabalho de Romero-Troncoso et al. (2014), uma metodologia similar também foi utilizada para avaliar uma ferramenta de estudo e análise de aspectos de motores de indução. De acordo com os autores, um grupo de 18 estudantes de Engenharia Elétrica participou da avaliação do software, a qual tinha cinco questões objetivas, cujos resultados apontaram um impacto positivo na opinião dos alunos, indicando uma experiência positiva no aprendizado e no interesse no assunto.

Existem muitos estudos na aplicação de softwares educacionais no ensino superior em diversas áreas, assim como na Engenharia Civil (BARRETTO et al., 2003), Ciência da Computação (NUGENT et al., 2006), Engenharia Eletrônica (ROSELLÓ et al., 2014), Engenharia da Computação (DJORDJEVIC et al., 2005) e Engenharia Mecânica (WANG et al., 2006; MUÑOZ-ABELLA et al., 2011). Por outro lado, não foi encontrado relato na literatura sobre a construção e a aplicação de um software educacional em Engenharia Florestal, demonstrando a inovação proporcionada pelo presente trabalho.

\section{CONCLUSÕES}

Este trabalho apresenta o desenvolvimento e a avaliação de um software de aprendizagem para os processos de amostragem da disciplina de Inventário Florestal. A aplicação é acessada pela Internet, onde 16 processos de amostragem podem ser exercitados pelos estudantes, cuja correção ocorre de forma on-line e dados individualizados são propostos.

Os resultados da avaliação do software demonstram que a percepção dos alunos é positiva ao benefício educacional, facilidade de uso e interesse futuro e que o software pode ser aplicado nas disciplinas de inventário florestal como complemento ao conteúdo. A avaliação indica também que o sistema de pontuação e comparação de desempenho teve concordância parcial entre os alunos.

O uso de tecnologia da informação e comunicação nas disciplinas dos cursos de engenharia, em especial na Engenharia Florestal, é muito limitado. Por outro lado, tem um potencial bastante grande, conforme demonstrado pelos resultados obtidos.

\section{REFERÊNCIAS}

BARRETTO, S. A.; PIAZZALUNGA, R.; RIBEIRO, V. A web-based $2 d$ structural analysis educational software. Computer Applications in Engineering Education, v. 2, n. 11, p. 83-92, 2003. 
BRASIL. Banco internacional de objetos educacionais. 2014. Disponível em: <http://objetoseducacionais2.mec.gov.br/2008> Acesso em: 28/02/2014.

BRASIL. Resolução $n^{\circ} 3$, de 2 de fevereiro de 2006. Institui as diretrizes curriculares nacionais para o curso de graduação em Engenharia Florestal e dá outras providências. Diário Oficial da União, Brasília: dois de fevereiro de 2006.

CIENTEC. Mata nativa. 2014. Disponível em: <http://www.matanativa.com.br> Acesso em: $10 / 03 / 2014$.

DESHPANDE, A.; HUANG, S. Simulation games in engineering education: a state-of-the-art review. Computer Applications in Engineering Education, v. 19, n. 3, p. 399-410, 2009.

DJORDJEVIC, J.; NIKOLIC, B.; MILENKOVIC, A. Flexible web-based educational system for teaching computer architecture and organization. Education, leee Transactions On, v. 2, n. 48, p. 264-273, 2005

DRUSZCZ, J.; NAKAJIMA, N.; PÉLLICO NETTO, S.; MACHADO, S.; ROSOT, N.; BAMBERG, R. Eficiência de duas variações estruturais do método de amostragem de área fixa em plantações de Pinus taeda. Revista Floresta, v. 43, n.3, p. 621-632, 2013.

EZMORTH. EZMorph. 2014. Disponível em: <http://ezmorph.sourceforge.net/index.html> Acesso em: $17 / 03 / 2014$.

FOREST, E. The ADDIE model: instructional design. 2014. Disponível em: <http://educationaltechnology.net/the-addie-model-instructional-design> Acesso em: 19/03/2014.

HUSH, B.; MILLER, C.; BEERS, T. Forest mensuration. New York: John Wiley, 3. ed. 1982.

INSTITUTO BRASILEIRO DE FLORESTAS. Software Faça Floresta. 2014. Disponível em: <http://www.facafloresta.com.br/index.php> Acesso em: 10/03/2014.

KAY, R.; KNAACK, L. Evaluating the learning in learning objects. Open Learning, v. 22, n. 1, p. 5-28, 2007.

LAAR, A.; AKÇA, A. Forest mensuration. Gottenberg: Springer, 2. ed. 2007.

MUÑOZ-ABELLA, B.; ÁLVAREZ-CALDAS, C.; RUBIO, L. Computer-aided tool for teaching mechanical clutch systems design. Computer Applications in Engineering Education, v. 19, n. 3, p. 493-500, 2011.

NUGENT, G.; SOH, L.-K.; SAMAL, A. Design, development, and validation of learning objects. Journal of Educational Technology Systems, v. 34, n. 3, p. 271-281, 2006.

ORACLE. The Java tutorials. 2014. Disponível em: <http://docs.oracle.com/javase/tutorial/getstarted/ intro/index.html> Acesso em: 17/03/2014.

PÉLLICO NETTO, S.; BRENA, D. A. Inventário florestal. Curitiba: Universidade Federal do Paraná. 1997.

PRESSMAN, R. Engenharia de software. São Paulo: Mcgraw-Hill, 6. ed. 2006.

PROJETO CR CAMPEIRO. Projeto CR Campeiro. 2014. Disponível em: <http://www.crcampeiro.net/novo/pages/apps_android> Acesso em: 10/03/2014.

QUEIROZ, W. Amostragem em inventário florestal. Belém: Universidade Federal Rural da Amazônia, 2012. 
ROMERO-TRONCOSO, R.; GARCIA-PEREZ, A.; CABAL-YEPEZ, E.; OSORNIO-RIOS, R. Experimental system for teaching induction motor faults during the startup transient and steady state. Computer Applications in Engineering Education, v. 1, n. 22, p. 33-38, 2014.

ROSELLÓ, E.; DACOSTA, J.; LADO, M.; MÉNDEZ, A.; SAMPEDRO, J.; COTA, M. Visual wavelet-lab: an object-oriented library and a GUI application for the study of the wavelet transform. Computer Applications in Engineering Education, v. 1, n. 22, p. 23-32, 2014.

SANQUETTA, C. R.; WATZLAWICH, L. F.; CÔRTE, A. D.; FERNANDES, L. D.; SIQUEIRA, J. D. Inventários florestais: planejamento e execução. Curitiba: Multi-Graphic, 2. ed. 2009.

SENCHA. Ext Js 3.4. 2014. Disponível em: <http://www.sencha.com/products/extjs3> Acesso em: $17 / 03 / 2014$.

SOUZA, A.; YONEZAWA, W.; SILVA, P. (2007). Desenvolvimento de habilidades em tecnologia da informação e comunicação (TIC) por meio de objetos de aprendizagem. In: PRATA, C.; NASCIMENTO, A. Objetos de aprendizagem. Brasília: SEED, 2007. 154 p.

THE APACHE POI PROJECT. Apache POI - The Java API for microsoft documents. 2014. Disponível em: <http://poi.apache.org> Acesso em: 17/03/2014.

THE APACHE SOFTWARE FOUNDATION. Apache commons: commons math. 2013. Disponível em: <http://commons.apache.org/proper/commons-math/index.html> Acesso em: 17/03/2014.

TIOBE SOFTWARE. Tiobe index for March 2014. 2014. Disponível em: <http://www.tiobe.com/index.php/content/paperinfo/tpci/index.html> Acesso em: 17/03/2014.

TREESOFTWARE. Treesoftware. 2013. Disponível em: <http://treesoftware.Iwsite.com.br> Acesso em: 10/08/2014.

WANG, Z.; LIU, Z.; TAN, J.; FU, Y.; WAN, C. A Virtual environment simulator for mechanical system dynamics with online interactive control. Advances in Engineering Software, v. 10, n. 37, p. 631-642. 2006.

WELTY, G. Formative evaluation in the ADDIE model. Journal of GXP compliance, v. 12, p. 66-73, 2008.

WILEY, D. Connecting learning objects to instructional design theory: a definition, a metaphor, and a taxonomy. Logan: The Edumetrics Institute, 2000. 35 p. 